\title{
Preschool Children's Learning Strategies
}

\author{
By Joy Cullen \\ Curtin University
}

W hen children start primary school they acquire a range of learning strategies which help them to tackle school tasks. Strategies such as checking instructions, and referring to books, charts or other classroom aids, help children to work systematically in school. Children who are good readers and achieve well on other school subjects are usually particularly competent in using these independent learning strategies.

In the informal learning environment of the preschool, children also practise many learning strategies. Preschoolers daily make decisions and choices about their activities and learn to make purposeful use of the many resources available to them. As they play in the sandpit or block area and join in dramatic play, preschoolers use language to direct themselves and others, and to respond to questions and instructions from other children. The preschooler who learns to make use of these strategies in the context of the concrete, play-oriented activities of the preschool acquires a repertoire of independent strategies to use later with the more abstract tasks of the school curriculum. Consequently, preschools have a valuable function of assisting children to acquire a range of independent strategies which will help them to become competent learners.

\section{An Australian Study of Young Children's Learning Strategies}

$\mathbf{R}$ ecently, I studied sixteen children from amongst 50 attending the afternoon sessions at two preprimary centres in Perth. In Western Australia, preprimary centres run sessional, preschool programmes for four- and five-year-olds.

In each centre, teachers selected four children who seemed ready to cope with school learning tasks, and four children who were not ready for school learning. This was done by observing how well each child: persisted with difficult tasks, paid attention in structured activities, co-operated with common goals and planning, extended activities creatively, used questions to assist learning, showed interest in literacy skills, showed curiosity and exploratory skills, returned to an uncompleted activity, used problem-solving skills, showed satisfaction with success, followed instructions related to a task, and used independent strategies to assist learning.

In this way, eight high-readiness children who were ready for school learning, and eight low-readiness children whose teachers believed they were not ready for school, were identified for further study. As far as possible high- and low-readiness children were matched by age, sex and any previous preschool or childcare experience. Average ages at the beginning of Term 1 were 4 years 9 months for the high-readiness children and 4 years 6 months, for the low-readiness children.

The sixteen children were observed by an early-childhood teacher who went to each centre once a week during Term 2. Observations were made of mat sessions with all the children together under the teacher's direction, of free-choice activities in the outdoor area, and of indoor activities (including both activities the children chose and activities at tables to which the teacher assigned children). In addition, interviews were carried out with children individually as they worked on an assigned activity at a table (usually art or craft supervised by the teacher's aide).

From the observations and the interviews we were able to build up a picture of the style of learning each child used. To do this, we first examined the observations carefully, using the following headings:

activity (e.g., manipulation, gross motor), social (e.g., peer parallel, adult interaction), language (e.g., social-response, self-question).

The social and language categories were also coded as positive or negative. At this point we looked again at each child's actions and language to identify effective learning strategies. In particular, we focused on:

Task persistence (extends activity, returns to activity)

Use of resources (experiments with resources, uses additional resources to solve problem)

Use of peer as a resource (asks for help, co-operation)

Use of adult as resource (asks for help, responds positively to adult's prompts)

Self as a resource for others (helps others - verbal or nonverbal, positive response to request for assistance)

Directs self (language which indicates direction of self)

Directs others (social language which indicates direction of others).

With the observations of the mat sessions where teachers were directing the children together on the mat, we looked only at whether the children attended and followed instructions. This was done because we found that in mat sessions there was little scope for children to use independent strategies. From the interviews we were able to judge children's awareness of learning strategies by looking at: the purpose of activity; the knowledge the child had of the materials or resources available for the activity; the use they made of adults as resources; their knowledge of independent strategies; and their ability to relate the activity to other experiences.

\section{Major Findings}

$T^{2}$ he observations showed that young children begin to use systematic strategies at preschool. Several contrasting patterns of behaviour distinguished the children who were ready for school and those who were not.

In the structured mat session run by the teacher, the children who were ready for school attended to the teacher and followed her instructions while those who were not ready were poor attenders who made inconsistent responses to instructions. In the outdoor area, the ready-for-school children used space and facilities more effectively, with 'purposeful movement' and 'the ability to extend activities'. In contrast, the children who were not ready 'flitted' from activity to activity or were distracted by interruptions, with only three of the eight children extending their play or returning to the same activity. The high-readiness children were able to direct others effectively in outdoor social play while low-readiness children used ineffective strategies such as negative talk and body language, for example 'that's mine', or snatching. These children also used peers or adults negatively as resources, for example, by complaints such as 'He took my spade' to an adult. Often they failed to get any response when trying to direct others.

In the indoor free-choice settings children in both groups were 
able to use resources for experimentation or problem-solving although the high-readiness children were more likely to integrate these actions into extended play sequences. Similarly, with indoor table activities, to which they were directed, seven of the high-readiness children were able to extend an activity whilst only two of the low-readiness children could manage this. Five low-readiness children required frequent adult instructions or prompts to sustain an activity; only one high-readiness child needed such help.

The interviews revealed that none of the children were greatly aware of independent strategies they could use on activities they had been directed to do at the tables. There were some isolated references to strategies such as 'decorate it' or 'use my imagination' and all but one of the 'ready' children were able to talk about using the same materials and resources to do another activity. For example, one high-readiness child said that he could make 'Probably a helicopter or plane' (while he was learning to fold paper). Talk of this sort does indicate that children are beginning to develop an awareness of strategies which could be used to extend an activity.

\section{Educational Implications}

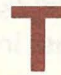
he findings have highlighted that informal play is a way in which children can practise independent learning strategies. For example, dramatic and constructive play sequences provide opportunities to use language for questioning, monitoring and guiding the actions of one's self and others, as well as opportunities for decision-making, problem-solving and experimentation with materials and resources.

Activities which are directed and controlled by the teacher make less provision for children to practise independent learning strategies. A little experimentation with resources and procedures did occur on these tasks but in general children followed instructions as the teacher guided, rather than planning their own goals and strategies. Relying upon adult guidance seems to account for at least part of the children's limited awareness of independent strategies. On tasks where (1) choice of procedures or resources is limited, (2) procedures are demonstrated, (3) materials are placed on tables for children's use, and (4) adult assistance is readily available, there is little need for children to make decisions or reflect about the actions involved in reaching a goal.

On the basis of these findings teachers who wish to create learning environment strategies in young children could consider the following recommendations:

1. Allow sufficient time for children to develop play sequences in informal play settings. Complex dramatic and constructive play sequences are unlikely to develop when informal play is viewed as sparetime activity or free-choice times are reduced to ten-minute slots.

2. Provide adult support in the form of prompts, questions, and praise, to increase the social and language skills of children who do not cope well in informal settings. Persisting at tasks, making decisions, using language for thinking, and using resources effectively can also be promoted through the interaction of adults and children. Adults should provide good models of strategic language and behaviour, and use appropriate language and actions in all situations that require persistence, attention or decisionmaking.

3. Consider ways to increase the amount of control children have over table activities and provide opportunities to talk about and use the things they make. Children's knowledge of learning strategies, and the language of learning, will develop as they experience choice, make decisions and talk about their activities with adults and other children.

4. Observe children in different settings, informal and teacher-directed. Identify the strategies they use systematically and intervene when children are adopting ineffective approaches to learning, for example, 'flitting' around play areas.

5. Use small groups (rather than whole group mat sessions) to encourage children who find attending difficult. This will help them to participate in discussions and activities which are led by an adult. Small groups facilitate meaningful participation.
Examples of Strategic Language and Behaviour
Self-directing language

'I'm going to climb up there.'

\section{Other-directing language}

... takes a spoonful of paint and smooths it over table, makes squiggles with right index finger, flattens out paint with palm of hand, moves paint around with palms of both hands, claps both hands together rubbing paint between hands, 'Good, do this like me. Do this too.' (to another child who is watching). Draws in paint on left palm. Rubs palms together. 'Look at this colour now.'

... goes to tyre, pulls it along the ground tipping water out, puts at bottom of the frame and uses it as step.

Steps on the tyre, climbs onto the frame. 'I'm going to do something grand.'

Cuts quickly, paper getting caught up, puts paper down and smooths it out, picks it up again and cuts slowly.

\section{Self as a resource}

'If you need help just call me.'

Takes block, adds to other child's 'road', takes one more and extends road (while watching another child building).
'First I have to get my sword.'

\section{Purposeful use of resources}

\section{Context}

climbing framedramatic play

climbing framegross motor

finger painting table - manipulation.

climbing frameproblem-solving

activity tableart, problem-solving

sandpit

block corner experimentation

\section{Notes}

Dr Joy Cullen is a Senior Lecturer in Education at Curtin University of Technology, Box U 1987, Perth, Western Australia 6001.

A full report of this research is available from Dr Cullen.

\section{Further Reading}

Copple, C.; Sigel, J.E.; Saunders, R. (1984). Educating the young thinker: Classroom strategies for cognitive growth. Hillsdale, N.J.: Lawrence Erlbaum.

Describes opportunities for developing thinking skills across the preschool curriculum, with particular emphasis on teachers' verbal interactions.

Cullen, J. (1982). Learning to cope with failure in the early school years. set, No.1, Item 6.

Describes 8-year-old children's knowledge of strategies for coping with initial failure on a school task.

Cullen, J. and Bosich, B. (1987). Young children's awareness of learning and their emergent literacy skills. Australian Journal of Early Childhood, Vol. 12, No.1, pp. 31-36.

Reports on relationships between emergent learning strategies and early literacy skills of children in their first year at school.

Pratt, C. (1985). Transition to school: A shift from development to learning. Australian Journal of Early Childhood, Vol. 10, No.1, pp. 11-16.

Discusses the importance of young children's developing control and awareness of thinking and language for their transition to formal instruction in the school context.

\section{Copying Permitted}

(C) Copyright on this item is held by NZCER and ACER who grant to all people actively engaged in education the right to copy it in the interests of better teaching; just acknowledge the source. 